\title{
Bronchial challenge tests: usefulness, availability and limitations
}

\section{Introduction}

Indirect challenges to assess bronchial hyperresponsiveness are being increasingly used both for research and for assessment in the routine pulmonary function laboratory. "Indirect challenges act by causing the release of endogenous mediators that cause the airway smooth muscle to contract with or without inducing microvascular leakage. Because the responses to these challenges are modified or completely inhibited by inhaled steroids, the airway response to the challenges may be a closer reflection of active airway inflammation" (fig. 1) [1]. In contrast, the direct tests, inhaled aerosols of histamine and methacholine act directly on receptors on the bronchial smooth muscle to cause contraction. While sensitive for detecting bronchial hyperresponsiveness a positive response to these agents is not specific for identifying asthma particularly at the higher concentrations. The best known of the indirect challenges is exercise. Other indirect challenges include eucapnic voluntary hyperpnoea, mannitol, adenosine monophosphate and hyperosmolar saline. All these indirect challenges are associated with release of mediators of bronchoconstriction. For this reason they have the potential to be used to identify presence of inflammatory cells particularly mast cells [2].

\section{Exercise}

\section{Usefulness}

Exercise testing is used to diagnose exerciseinduced bronchoconstriction (EIB). The term EIB describes the transient increase in airways resistance that follows vigorous exercise. EIB is thought to result from transient dehydration of the airway surface in response to conditioning the inspired air. The diagnosis of EIB is made on measurement of changes in lung function in response to exercise. The type, duration and intensity of exercise and the water content of the air inspired and the time since EIB was last provoked are important factors when identifying EIB and its severity $[3,4]$.

Objective testing with exercise for EIB is clinically very useful because the symptoms often associated with vigorous exercise are similar to those reported by asthmatics. Importantly healthy people without EIB can have these "asthma" symptoms and those with EIB may not have these symptoms. Clinically, having a properly performed exercise test to identify EIB avoids both the over diagnosis and under diagnosis of EIB when symptoms are relied upon to make the diagnosis. In addition it is important to have objective evidence of EIB for people seeking occupations (defence, police) or for recreation (diving) where EIB would not be desirable.

EIB is identified by documenting a fall in forced expiratory volume in $1 \mathrm{~s}$ (FEV1) of 10\% (or $15 \%$ ) or more from the preexercise value within 20-30 mins after exercise $[3,5,6]$. The lowest values are usually measured within 5-12 mins. The FEV 1 is measured two or three times at various time intervals after exercise for example, 1, 3, 5, 10, 15, 20, 30 minutes and the highest of the acceptable values (using ERS/ATS criteria) is recorded at each interval $[3,4]$. Recovery from EIB is spontaneous and FEV 1 usually returns to $95 \%$ of the baseline value within 30-60 mins.

\section{S.D. Anderson}

Department of Respiratory and Sleep Medicine, Royal Prince Alfred Hospital Camperdown NSW Australia.

\section{Correspondence \\ S.D. Anderson \\ Department of Respiratory and Sleep Medicine \\ Royal Prince Alfred Hospital Camperdown \\ NSW}

Australia 2050

sandra.anderson@sydney.edu.au

\section{Competing interests}

S.D. Anderson is the inventor of the mannitol test that is used for bronchial challenge testing. The intellectual property (IP) is owned by her employer, Sydney South West Area Health Service (SSWAHS), which licensed the IP to Pharmaxis Ltd in 2001. S.D. Anderson purchased shares with her own money at the time the company went public in 2003. She owns 30,000 shares and holds no options. SSWAHS receives royalties for sales of the mannitol test (Aridol and Osmohale). S.D. Anderson receives a $10 \%$ share of the royalties paid to SSWAHS. S.D. Anderson's department at Royal Prince Alfred Hospital received money for Phase 3 trials for the mannitol that contributed to the registration of the mannitol test with the regulatory authorities. The same department now receives $30 \%$ of the royalties paid to SSWAHS. Since leaving full-time employment in March 2009, S.D. Anderson acted as a paid consultant from time to time for Pharmaxis Ltd. She also gives lectures for Pharmaxis Ltd and its distributors, for which she has received honoraria. She has no other conflict of interest.

HERMES syllabus link: module D.1.5, D.1.6 


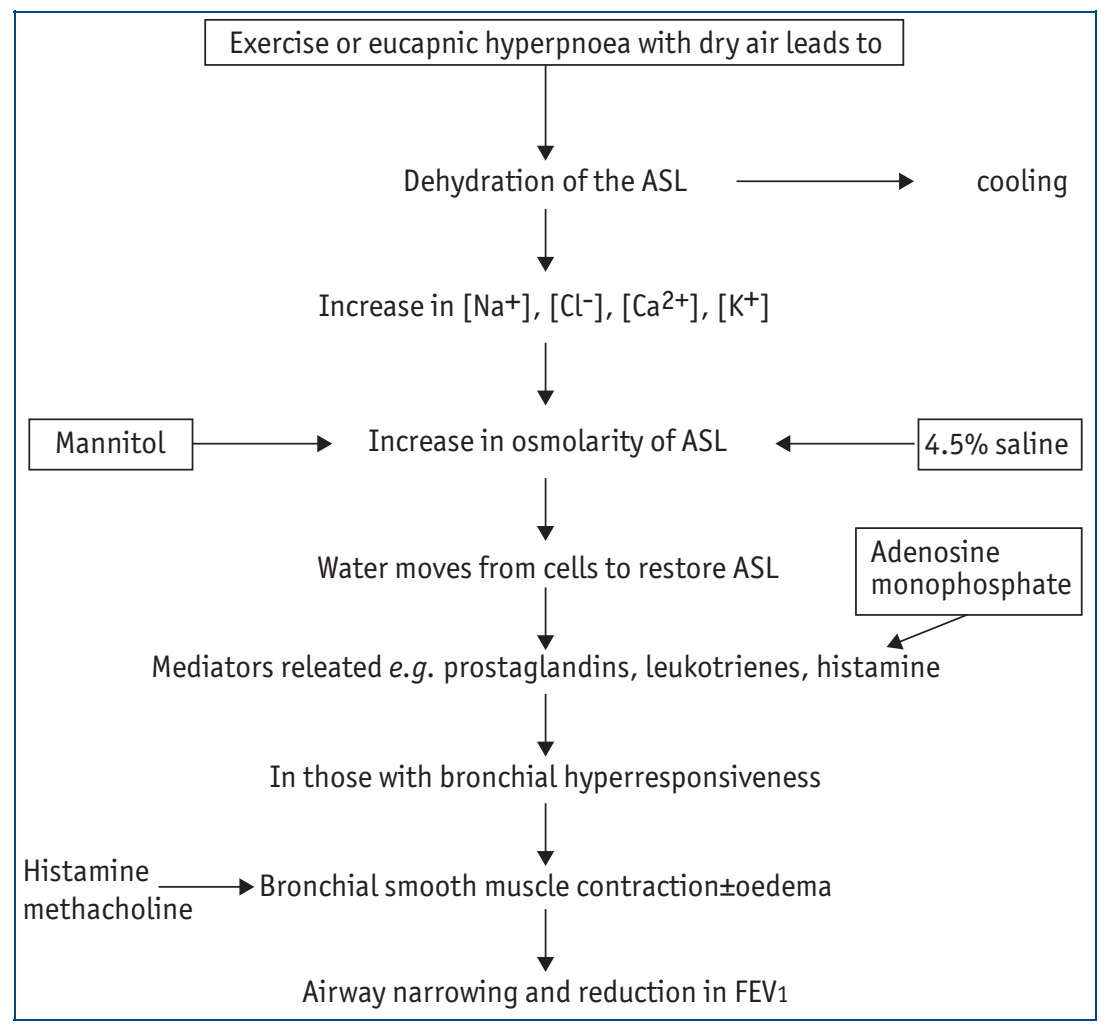

\section{Figure 1}

The events that lead to airway narrowing and a reduction in forced expiratory volume in $1 \mathrm{~s}$ in response to different indirect challenge tests. While hyperpnoea, mannitol and $4.5 \%$ saline all act to increase osmolarity that causes mediators to be released, adenosine acts to release mast cell mediators through a specific receptor on the mast cell. ASL: airway surface liquid; FEV1: forced expiratory volume in $1 \mathrm{~s}$. Modified from [2] with permission from the publisher.

\section{Availability}

The availability to perform vigorous exercise is relatively easy outside the laboratory. Exercising in the field performing the same exercise routine that produces the subject's symptoms is very useful. The ready availability of hand-held spirometers has made testing in the field easier than ever before. While peak expiratory flow (PEF) was once commonly used for identifying EIB it is not as repeatable as $\mathrm{FEV} 1$ and is no longer recommended. In very young children measurement of FEV 0.5 can be useful [7]. Field testing with sports specific exercise for athletes usually means performing the actual sport for as long as it takes to provoke the symptoms. This period may be as short as a few minutes for ice skating or as long as 20-30 mins for cross-country skiing [8]. Field testing performing running exercise has been used for evaluating school children for EIB [6].

The ability to perform vigorous exercise in the laboratory is dependent on the availability of suitable ergometers. Whilst exercise equipment is frequently available in lung function laboratories, the choice of ergometers is usually limited to treadmill and bicycle. It may not be informative to run or to cycle a subject who has their symptoms whilst rowing or swimming or skiing. However, it is usually easier to have the right inspired air conditions during exercise in a laboratory as most have available medical grade air that is dry. Finally, the appropriate equipment for measuring the intensity of exercise, i.e. by measuring ventilation (rather than heart rate), is more readily available in a laboratory and even some simple household gas meters can be used for this purpose. All laboratories performing bronchial provocation tests would be expected to have the appropriate spirometers and safety equipment, and personnel readily available for resuscitation.

\section{Limitations}

The limitation to field exercise is having the right equipment that includes a spirometer, a measure of exercise intensity such as a heart rate meter, a nose-clip for exercise, safety equipment and the ability to measure temperature and humidity to ensure that the water content is $<10 \mathrm{mg}$ of water per litre of air. This represents $\sim 50 \%$ humidity at $23^{\circ} \mathrm{C}[6]$. At temperatures $<10^{\circ} \mathrm{C}$ the air will always be sufficiently dry. As severe falls in FEV1 can occur it is important to have available a bronchodilator, oxygen and a handheld pulse oximeter.

The greatest limitation to exercise testing for EIB in the laboratory is the wide variety of exercise protocols that are used, some of which are simply inadequate to provoke EIB. Most laboratories report a low prevalence of positive tests for EIB and this is the major reason for the switch to using other tests. The exercise required to diagnose EIB is not suited to a continuous increase in intensity and it is necessary to reach the maximum work load rapidly within a few minutes and lower the load later if needed. Starting with very a low work-load or using the classic progressive exercise protocols for assessing maximum working capacity will lead to many false negative results. The reason probably relates to release of broncho-dilating substances, such as prostaglandin $E_{2}$, at low ventilation that serve to protect the airways from bronchoconstriction.

To avoid false negative tests and give the greatest likelihood to identify EIB, the intensity of exercise needs to be sufficient to raise the ventilation and heart rate close to the desired value within the first 2-3 min of exercise. This 
intensity needs to be maintained for $\geqslant 4$ mins in children and 5 or 6 mins in adults. This is usually easier to achieve by running on a treadmill than cycling. Specific protocols for guidance are published [6, 8-12] and two examples of these are summarised in tables 1 and 2. Some of these protocols involve running while others involve cycling or involve exercise in the field. In brief, the study protocols re commend breathing dry air with a nose clip in place while running or cycling at a ventilation to reach $\sim 17.5-21$ times $\mathrm{FEV} 1$ during the first 2-3 mins of exercise or a load sufficient to raise the heart rate to $80-90 \%$ of predicted maximum ( $\sim 220$ - age in yrs). Severity of ElB for an individual is dependent on rate of water lost from the lower airways which is why ventilation is the primary determinant of EIB and why the inspired air needs to be dry. The higher the ventilation, the dryer the air the greater the number of airways recruited into the conditioning process and the greater the chance of identifying EIB $[13,14]$.

There are many factors, other than intensity and duration of exercise, that can affect the response to exercise. These include, recent intake of asthma medications, recent or intermittent warm up exercise and all increase the likelihood of a false negative. In contrast recent exposure to inhaled or ingested allergens may increase the severity of the response the subject may normally have. Furthermore, there is inherent variability in EIB (25-50\% variation in the \% fall) such that a diagnosis of EIB may be "missed" if only one test is performed (fig. 2) [10]. Exercise is thus not the best laboratory test for identifying potential for EIB in the field or to identify the bronchial hyperresponsiveness of asthma.

\section{Eucapnic voluntary hyperpnoea}

\section{Usefulness}

The many variables that need attending in order to minimise the likelihood of a false negative test and the safety issues related to exercise test ing itself led to the development and use of the eucapnic voluntary hyperpnoea (EVH) test $[15,16]$. This test is also known as eucapnic hyperventilation or isocapnic hyperventilation. There are advantages in using $\mathrm{EVH}$ in the laboratory. The $\mathrm{EVH}$ test requires less equipment and fewer personnel and it is quieter and less stressful to perform than exercise at the equivalent level of ventilation. The duration of the ventilation and the condition of the air inspired can be varied if required to evaluate the conditions under which exercise is performed i.e. cold air etc. An abnormal response is a $\geqslant 10 \%$ fall in FEV 1 from the baseline value and it is recommended that the fall be sustained for two consecutive readings over 5 mins after completion of the hyperpnoea.

$\mathrm{EVH}$ is the most useful test to identify EIB in athletes $[17,18]$ and defence force recruits $[15]$ with normal lung function. For this application the standard protocol of 6 mins of a target ventilation of 30-times FEV1 is more sensitive than laboratory-based exercise tests and the frequency of false negative test results is low $[19,20]$. This standardised protocol is not recommended for identifying EIB in known asthmatics who are symptomatic or uncontrolled or whose lung function is not normal. The clinical utility of using a lower ventilation (21times FEV1 for 6 mins) has been reported in

\section{Table 1 Field running protocol for identifying exercise-induced bronchoconstriction in children}

$\begin{array}{ll}\text { Group } & \text { Children aged } 6-11 \text { yrs } \\ \text { Measurement } & \mathrm{FEV} 1 \text { at } 3,5 \text { and } 10 \text { mins, and more if required; } \\ & \mathrm{FEV} 1 \% \text { pred pre-exercise: } \geqslant 75 \% \\ \text { Mode of exercise } & \text { Free running on the flat at } 7 \mathrm{~km} \cdot \mathrm{h}^{-1} \\ \text { Index of intensity } & 85-90 \% \text { pred of maximum; heart rate of } \\ & 180-190 \text { beats } \cdot \mathrm{min}^{-1} \\ \text { Duration } & 6 \text { mins } \\ \text { Inspired air } & \text { Absolute water content }<10 \mathrm{mgH}_{2} \mathrm{O} \cdot \mathrm{L}^{-1} \text { equivalent } \\ & \text { to } 23^{\circ} \mathrm{C}<50 \% \text { relative humidity } \\ \text { Ventilating } & \text { Via mouth with nose-clip in place } \\ \text { Positive response } & \mathrm{FEV} 1 \% \text { decrease } \geqslant 13 \% \\ \text { FEV1: forced expiratory volume in } 1 \mathrm{~s} ; \% \text { pred: } \% \text { predicted. Modified from }[6] \text { with permission from the publisher. }\end{array}$


Table 2 Treadmill protocol to identify exercise-induced bronchoconstriction used in adults and children

$\begin{array}{ll}\text { Group } & \text { Adults and children, aged } 6-50 \text { yrs } \\ \text { Measurement } & \text { FEV1 pre and post and at } 5,10,15 \text { and } \\ & 30 \text { mins } \\ \text { Mode of exercise } & \text { Started by walking then running on a } \\ & \text { treadmill at } 4.1 \mathrm{~km} \cdot \mathrm{h}^{-1} \text { on a } 2.5 \% \text { slope } \\ & \text { Heart rate of } 80-90 \% \text { maximum } \\ & \left(220 \text { beats } \cdot \mathrm{min}^{-1} \text { minus age in years }\right) \\ \text { Index of intensity } & \text { within } 2 \text { mins and maintained for } 6 \text { mins } \\ & \text { Best measured directly }>17.5 \text {-times } \mathrm{FEV}_{1} \\ \text { Ventilation } & \text { Can be based on workload and } \mathrm{VO}_{2} \\ \text { Estimated ventilation } & 8 \text { mins } \\ \text { Target duration } & \text { Medical air, } 20-30{ }^{\circ} \mathrm{C} \\ \text { Inspired air } & \mathrm{FEV} 1 \% \text { decrease } \geqslant 10 \% \\ \text { Positive response } & \end{array}$

FEV1: forced expiratory volume in $1 \mathrm{~s} ; \%$ pred: \% predicted; $\mathrm{VO}_{2}$ : oxygen consumption. Modified from [10] under creative commons and [11] with permission from the publisher.

patients referred for routine testing for EIB and was diagnostic in $81 \%$ of subjects. The clinical usefulness of testing with $\mathrm{EVH}$ is in reducing the over- and under-diagnosis of EIB that arises from relying on symptoms.

\section{Availability}

Although $\mathrm{EVH}$ for 4 mins with cold air was frequently performed in laboratories in the early 1980s [21], today EVH is mostly used to test elite athletes [22-26]. The reason for this change may have related to the perceived need to cool the air and the definite requirement to control the end-tidal carbon dioxide in order to maintain eucapnia over a wide range of ventilation. Both

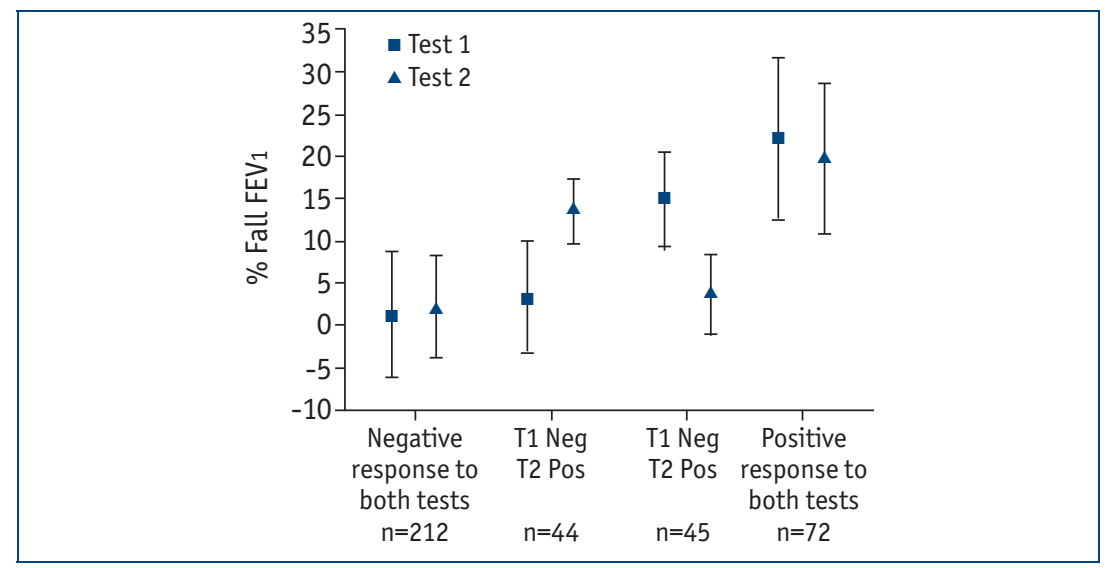

Figure 2

Response to two identical exercise tests (T1 and T2) in 278 adults and 95 children with signs and symptoms of asthma but no definite diagnosis. Note that for 89 subjects, the exercise test was positive on only one of the two tests. For 44 subjects, the negative test was the first one and thus on one test exercise-induced bronchoconstriction would have been missed. FEV1: forced expiratory volume in $1 \mathrm{~s}$ Modified from [10] under creative commons. of these needs added to the cost of the test. The technical issues, but not the cost issue, have in part been overcome by using a commercially prepared gas mixture of $4.9-5 \% \mathrm{CO}_{2}, 21 \% \mathrm{O}_{2}$ and balanced $\mathrm{N}_{2}$ inhaled at room temperature for 6 mins. Under these conditions, eucapnia is maintained at ventilations between 40 and $105 \mathrm{~L} \cdot \mathrm{min}^{-1}$ [27]. Machines are commercially available to mix gases.

\section{Limitations}

The major limitation in using the $\mathrm{EVH}$ tests is the need to maintain eucapnia over a wide range of ventilation. The FEV1 needs to be $\geqslant 1.5 \mathrm{~L}$ and ventilation needs to be $40-105 \mathrm{~L} \cdot \mathrm{min}^{-1}$ to use the prepared gas mixture. If the FEV1 value is lower or the ventilation is outside the limits, then the endtidal $\mathrm{CO}_{2}$ needs to be monitored for eucapnia. This is important because hypocapnia is a bronchoconstricting stimulus in itself and hypercapnia is dangerous because it produces acidosis.

A second limitation is the potential to induce rapid and severe $(>30 \%)$ fall in $\mathrm{FEV} 1$ postchallenge (fig. 3) [28]. The EVH test uses one level of ventilation for 6 mins and, as with exercise, the bronchoconstriction rapidly follows cessation of the hyperpnoea. For this reason, the original standardised protocol of 30-times FEV1 for 6 mins is only appropriate for identifying EIB who perform exercise regularly and at high intensity and is not the test of choice in known asthmatics. If $\mathrm{EVH}$ is the only test available then ventilation of 21-times FEV1 rather than 30-times FEV1 is recommended $[29,30]$ and consideration should be given to shortening the duration to 4 mins rather than 6 mins. This lower level of ventilation is equivalent to $60 \%$ of maximum voluntary ventilation and is similar to what would be reached during intense exercise in the average healthy athletically untrained person [9].

There is a report that the EVH is uncomfortable to perform [24]. There may be several reasons for this. First, because the ventilation needs to be very high, the resistance of the equipment needs to be very low. If there is just one part of the apparatus that is too narrow, the resistance will increase and it will be difficult for the subject to inhale at the high flow rates required. Secondly, the dry air is difficult for some subjects who may be troubled by cough. Finally, for athletes with an FEV1 greater than normal, the target ventilation of 30-times FEV1 may simply be too high and should be reduced to 
a comfortable level that still exceeds 21-times FEV1.

\section{Dry powder mannitol}

\section{Usefulness}

Mannitol is highly specific for identifying the bronchial hyperresponsiveness that is consistent with asthma. In well-defined groups there are few false-positive test results [31-34]. As with other indirect challenges, mannitol does not cause the bronchial smooth muscle to contract directly, as inhalation of histamine or methacholine do, but rather, it acts indirectly on inflammatory cells (most likely the mast cell) to induce release of mediators, such as prostaglandin $D_{2}$, leukotriene $E_{4}$ and histamine. In those with hyperresponsiveness, bronchial smooth muscle exposure to these mediators will stimulate specific receptors on the muscle causing it to contract and the airways to narrow [35]. Thus, in addition to a hyperresponsive muscle, a positive response to mannitol indicates that there are sufficient numbers of inflammatory cells, with a sufficient concentration of mediator to cause airway narrowing. In a person negative to mannitol one or more of these three components will be missing. It is important to remember that most stimuli that provoke an attack of asthma in daily life act indirectly. Normal variation in cell numbers, concentration of mediators and responsiveness of the muscle mean that the airway responses will vary over time and in response to treatment with anti-inflammatory agents.

Mannitol was chosen as an osmotic stimulus because it is stable as a dry powder at high relative humidity, has many medical applications and is generally regarded as a safe molecule. The mannitol inhalation test has one standard protocol and dry powder device for delivery. The FEV 1 is measured $60 \mathrm{~s}$ after each dose of mannitol $(0,5,10,20,40,80,160,160$, $160 \mathrm{mg}$ ). The dose of 80 and $160 \mathrm{mg}$ are given as multiples of $40 \mathrm{mg}$ capsules. The subject is asked to exhale completely before taking a controlled deep inspiration from the device (flow rate best kept at $60-90 \mathrm{~L} \cdot \mathrm{min}^{-1}$ ) and to hold their breath for $5 \mathrm{~s}$ then exhale through their mouth before removal of the nose clip. The test result is expressed as the provoking dose to induce a 15\% fall in FEV1 (PD15). The 15\% cut off point from the post $0 \mathrm{mg}$ capsule is based on the mean \% fall in FEV 1 plus 2 standard deviations documented in healthy non-asthmatic subjects (fig. 4) [31, 36]. PD15 is a measure of

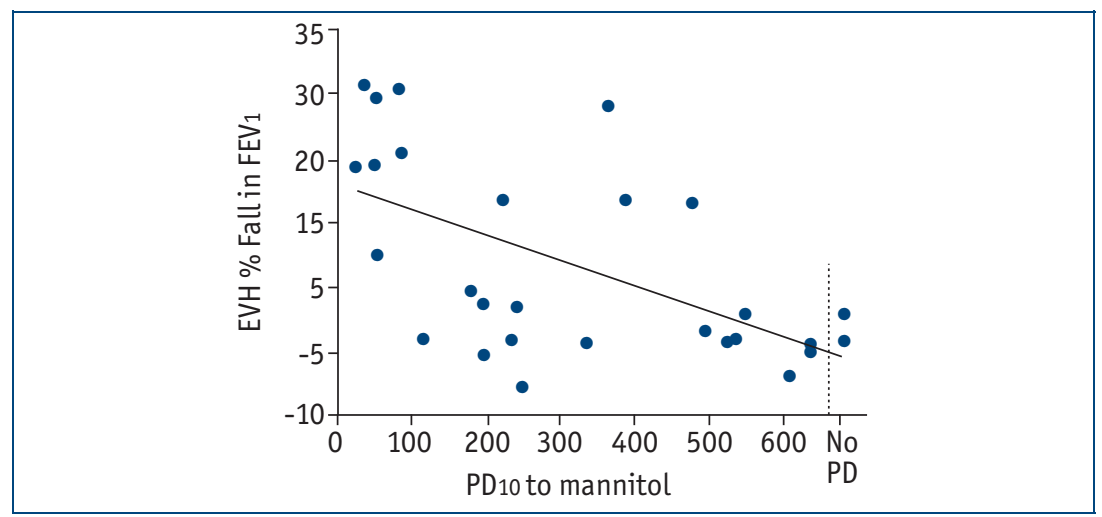

Figure 3

$\%$ decrease in forced expiratory volume in $1 \mathrm{~s}$ (FEV1) to eucapnic hyperpnoea (EVH) in relation to the provoking dose to cause a 10\% fall in FEV 1 after mannitol inhalation (PD10) in elite athletes. Note the high \% fall in FEV1 after EVH in some subjects. Modified from [28] with permission from the publisher.

sensitivity. In phase 3 trials, $80 \%$ of subjects with a positive response to mannitol responded after 10 capsules or six dose steps (fig. 5) [31].

The progressive nature of the protocol for the mannitol test to achieve a $15 \%$ fall in FEV1 means that the large falls in FEV 1 often observed with exercise and $\mathrm{EVH}$ are avoided. The mean final fall in $\mathrm{FEV} 1$ is $\sim 21 \%[31,37]$. Recovery of $\mathrm{FEV} 1$ is spontaneous and the median time to recovery to $95 \%$ baseline value is reported as 21.6 mins. The response-dose ratio (RDR) is a measure of reactivity and is defined as the $\%$ fall in FEV1 per mg of mannitol. RDR have been used to compare responses to exercise and for diagnosis of asthma $[32,38]$

The reported mean time for a positive mannitol test is $<18$ mins and for a negative test is $<27$ mins [31]. Repeatability of the test is

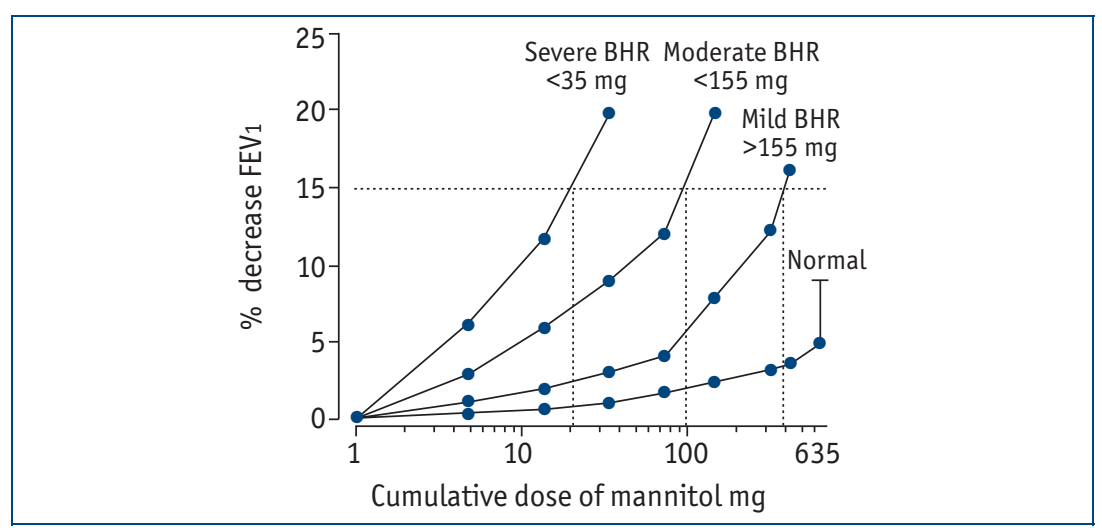

Figure 4

The values for the provoking dose of mannitol to cause a $15 \%$ decrease $\left(P D_{15}\right)$ in forced expiratory volume in $1 \mathrm{~s}$ (FEV 1 ) showing the different levels of bronchial hyperresponsiveness to mannitol and the values obtained in normal healthy subjects. Modified from [36] with permission from the publisher. 


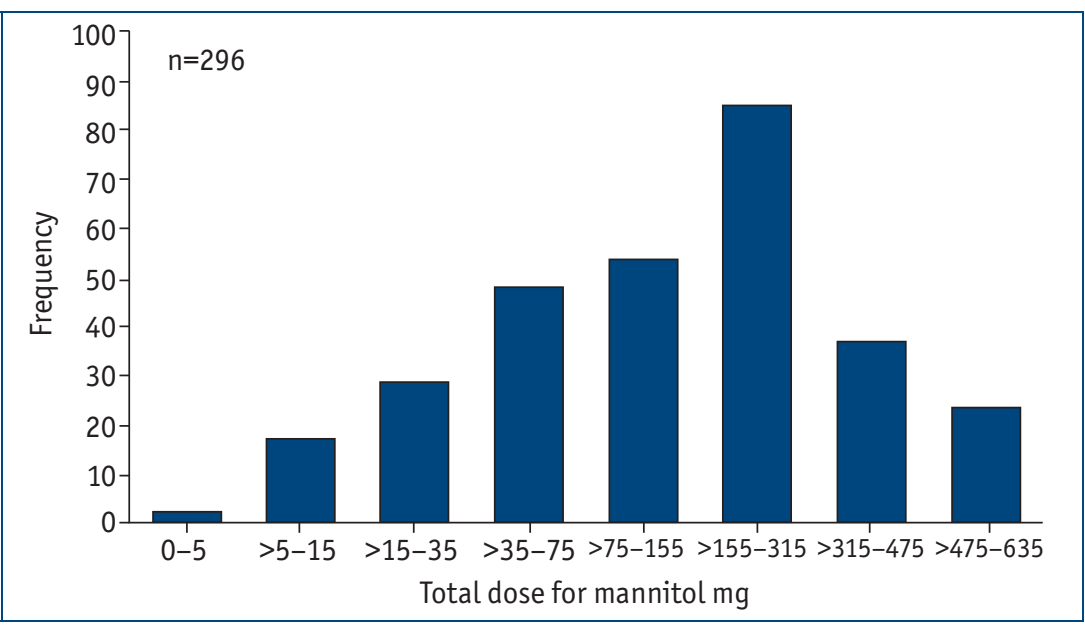

Figure 5

The number of asthmatic subjects, with a 15\% decrease in forced expiratory volume in $1 \mathrm{~s}$ to mannitol at each dose interval, in the initial Phase 3 trial [31]. Note that $80 \%$ of the 296 subjects responded with a positive test result with a cumulative provoking dose of mannitol less than $315 \mathrm{mg}$ or 10 capsules. Modified from [31] under creative commons.

\pm 1.0 doubling dose in adults and children [39, 40]. The mannitol test kit using dry powder has overcome many of the technical and hygiene issues related to the use of wet aerosols for bronchial provocation and collection of sputum $[41,42]$.

\section{Availability}

Bronchial provocation tests using dry powder mannitol, known as Aridol ${ }^{\mathrm{TM}}$ or Osmohale ${ }^{\mathrm{TM}}$, have been approved by regulatory authorities in Europe, Asia, Australia and the USA and are available in 23 countries. The mannitol test comes in a kit, containing prepacked capsules and an inhaler device.

\section{Limitations}

As with any osmotic challenge, inhalation of mannitol will provoke a person to cough. The large phase-3 trials of 592 people reported that $85 \%$ of subjects experienced cough [31]. The majority $(71 \%)$ of the subjects had only occasional cough that did not delay the administration of the next dose. For $13.2 \%$ of subjects however there was some delay to the next dose. In only $1.3 \%$ of subjects was the challenge stopped for cough. Other adverse events on the day of study included pharyngeal pain (2.6\%), throat irritation (1.1\%), and nausea (1.1\%). The first two are alleviated by sips of water during challenge [31].

The rationale for inhaling mannitol as a surrogate for exercise to identify EIB is based on the stimulus i.e. increasing osmolarity of the airway surface liquid to mimic dehydration and the mechanism for bronchoconstriction i.e. via inflammatory mediators being common to both. In those with clinically recognised asthma, not taking inhaled steroids, the sensitivity for mannitol to identify EIB provoked by exercise or $\mathrm{EVH}$ is high and the severity of airway narrowing can be predicted from the PD15 to mannitol $[28,43,44]$. The relationship is not as clear for people with signs of asthma without a definite diagnosis [37, 45]. In one study, 30\% with EIB ( $>15 \%$ fall in FEV1) were not identified either with mannitol or with methacholine [37]. However, in the same study, the frequency of bronchial hyperresponsiveness to mannitol, defined as a $15 \%$ fall in $\mathrm{FEV} 1$, was 1.6-imes that found with a single exercise test. Similar results were recently reported in 99 children referred for possible diagnosis of asthma with 21 positive to exercise and 29 to mannitol with a test agreement of $84 \%$ [45]. A similarly high frequency of responsiveness to mannitol (92\%) with a lower response to exercise (36\%) has also been reported by others [46].

The response to mannitol is dependent on progressively increasing an osmotic gradient. To achieve this, the subject needs to inhale each dose of mannitol as quickly as possible after the last dose. The sensitivity of mannitol to identify EIB is greater when the test time is $<35$ mins [37] and for optimal use the test should be no greater than 35 mins for the full $635 \mathrm{mg}$.

\section{Conclusion}

Exercise testing in the laboratory, to identify EIB has limited clinical utility. The reason is that it is hard to control the many factors that affect the severity of the airway response and, as a result, there is great variability and a high rate of false negative test results. Many of these factors were overcome by the development of the eucapnic voluntary hyperpnoea test and this is considered the best test to identify EIB in the laboratory. The reason is that $\mathrm{EVH}$ requires breathing dry air at a ventilation rate beyond the maximum achievable by most people, during exercise so the occurrence of falsenegative tests is minimised. As EVH provides a potent stimulus and large falls in FEV 1 can occur, the test is most appropriately used to identify EIB in subjects with normal lung function who perform exercise regularly and at high intensity. The response to both exercise and $\mathrm{EVH}$ is reported as maximum \% fall in FEV1 which is a measure of reactivity. Dry powder mannitol, delivered by inhalation as an aerosol, 
provides a similar stimulus to the airways, as exercise and $\mathrm{EVH}$, in that the same inflammatory mediators are released in response to the challenge. Challenge with mannitol differs from exercise and $\mathrm{EVH}$ in that the airway response is measured after each dose, a technique that avoids large falls in FEV1. With mannitol, both sensitivity (PD15) and reactivity (RDR) are measured. The same mannitol test kit and inhaler device has regulatory approval in four continents. The standardised protocol and published data on safety and efficacy in large numbers of subjects give mannitol the opportunity to become the "gold standard" over other indirect challenge tests (exercise, eucapnic voluntary hyperpnoea, adenosine monophosphate, hyperosmolar saline) for identifying bronchial hyperresponsiveness and the potential for EIB in the routine laboratory.

\section{References}

1. Joos GF, O'Connor B, Anderson SD, et al. Indirect airway challenges. Eur Respir J 2003; 21: 1050-1068.

2. Anderson SD. Indirect challenge tests. Chest 2010; 138: 25S-30S.

3. Crapo R0, Casaburi R, Coates AL, et al. Guidelines for methacholine and exercise challenge testing: 1999. Am J Respir Crit Care Med 2000; 161: 309-329.

4. Anderson SD, Brannan JD. Methods for 'indirect' challenge tests including exercise, eucapnic voluntary hyperpnea and hypertonic aerosols. Clin Rev Allergy Immunol 2003; 24: 63-90.

5. Sterk PJ, Fabbri LM, Quanjer PH, et al. Airway responsiveness: standardized challenge testing with pharmacological, physical and sensitizing stimuli in adults. Eur Respir J 1993; 6: 53-83.

6. Haby MM, Anderson SD, Peat JK, et al. An exercise challenge protocol for epidemiological studies of asthma in children: comparison with histamine challenge. Eur Respir J 1994; 7: 43-49.

7. Vilozni D, Bentur L, Efrati 0, et al. Exercise challenge test in 3-6 year old asthmatic children. Chest 2007; 132: 497503.

8. Rundell KW, Im J, Mayers LB, et al. Self-reported symptoms and exercise-induced asthma in the elite athlete. Med Sci Sports Exerc 2001; 33: 208-213.

9. Anderson SD, Lambert S, Brannan JD, et al. Laboratory protocol for exercise asthma to evaluate salbutamol given by two devices. Med Sci Sports Exerc 2001; 33: 893-900.

10. Anderson SD, Pearlman DS, Rundell KW, et al. Reproducibility of the airway response to an exercise protocol standardized for intensity, duration, and inspired air conditions, in subjects with symptoms suggestive of asthma. Respir Res 2010; 11: 120.

11. Weiler JM, Nathan RA, Rupp NT, et al. Effect of fluticasone/salmeterol administered via a single device on exerciseinduced bronchospasm in patients with persistent asthma. Ann Allergy Asthma Immunol 2005; 94: 65-72.

12. Carlsen KH, Engh G, Mørk M. Exercise induced bronchoconstriction depends on exercise load. Respir Med 2000; 94: 750-755.

13. Anderson SD, Daviskas E. The mechanism of exercise-induced asthma is ...... J Allergy Clin Immunol 2000; 106: 453-459.

14. Anderson SD, Kippelen P. Stimulus and mechanism of exercise-induced bronchoconstriction. Breathe 2010; 7: 25-33.

15. Argyros GJ, Roach JM, Hurwitz KM, et al. Eucapnic voluntary hyperventilation as a bronchoprovocation technique. Development of a standardized dosing schedule in asthmatics. Chest 1996; 109: 1520-1524.

16. Anderson SD, Argyros GJ, Magnussen H, et al. Provocation by eucapnic voluntary hyperpnoea to identify exercise induced bronchoconstriction. Br J Sports Med 2001; 35: 344-347.

17. Anderson SD, Fitch K, Perry CP, et al. Responses to bronchial challenge submitted for approval to use inhaled $\beta 2$ agonists prior to an event at the 2002 Winter Olympics. J Allergy Clin Immunol 2003; 111: 44-49.

18. Dickinson J, McConnell A, Whyte G. Diagnosis of exercise-induced bronchoconstriction: eucapnic voluntary hyperpnoea challenges identify previously undiagnosed elite athletes with exercise-induced bronchoconstriction. Br J Sports Med 2010; 1: 20.

19. Mannix ET, Manfredi F, Farber MO. A comparison of two challenge tests for identifying exercise-induced bronchospasm in figure skaters. Chest 1999; 115: 649-653.

20. Rundell KW, Wilber RL, Szmedra L, et al. Exercise-induced asthma screening of elite athletes: field vs laboratory exercise challenge. Med Sci Sports Exerc 2000; 32: 309-316.

21. Zach M, Polgar G, Kump H, et al. Cold air challenge of airway hyperreactivity in children: practical application and theoretical aspects. Pediatr Res 1984; 18: 469-478.

22. Dickinson J. Screening elite winter athletes for exercise induced asthma: a comparison of three challenge methods. Brit J Sports Med 2006; 40: 179-182.

23. Kippelen P, Larsson J, Anderson SD, et al. Acute effects of beclomethasone on hyperpnea-induced bronchoconstriction. Med Sci Sports Exerc 2010; 42: 273-280.

24. Stadelmann K, Stensrud T, Carlsen KH. Respiratory symptoms and bronchial responsiveness in competitive swimmers. Med Sci Sports Exerc 2011; 43: 375-381.

25. Sue-Chu M, Brannan JD, Anderson SD, et al. Airway hyperresponsiveness to methacholine, adenosine5monophosphate, mannito, eucapnic voluntary hyperpnoea and field exercise challenge in elite cross country skiers. Brit J Sports Med 2010; 44: 827-832.

26. Aronsson D, Tufvesson E, Bjermer L. Comparison of central and peripheral airway involvement before and during methacholine, mannitol and eucapnic hyperventilation challenges in mild asthmatics. Clin Respir J 2011; 5: 10-18

27. Phillips YY, Jaeger JJ, Laube BL, et al. Eucapnic voluntary hyperventilation of compressed gas mixture. A simple system for bronchial challenge by respiratory heat loss. Am Rev Respir Dis 1985; 131: 31-35.

28. Holzer K, Anderson SD, Chan H-K, et al. Mannitol as a challenge test to identify exercise-induced bronchoconstriction in elite athletes. Am J Respir Crit Care Med 2003; 167: 534-547.

29. Smith CM, Anderson SD, Seale JP. The duration of action of the combination of fenoterol hydrobromide and ipratropium bromide in protecting against asthma provoked by hyperpnea. Chest 1988; 94: 709-717. 
30. Brummel NE, Mastronarde JG, Rittinger D, et al. The clinical utility of eucapnic voluntary hyperventilation testing for the diagnosis of exercise-induced bronchospasm. J Asthma 2009; 46: 683-686.

31. Brannan JD, Anderson SD, Perry CP, et al. The safety and efficacy of inhaled dry powder mannitol as a bronchial provocation test for airway hyperresponsiveness: a phase 3 comparison study with hypertonic (4.5\%) saline. Respir Res 2005; 6: 144.

32. Sverrild A, Porsbjerg C, Thomsen SF, et al. Diagnostic properties of inhaled mannitol in the diagnosis of asthma: a population study. J Allergy Clin Immunol 2009; 124: 928-932.

33. Sverrild A, Porsbjerg C, Thomsen SF, et al. Airway hyperresponsiveness to mannitol and methacholine and exhaned nitric oxide: A random-sample population study. J Allergy Clin Immunol 2010; 126: 952-958.

34. Anderson SD, Brannan JD. Bronchial provocation testing: the future. Curr Opin Allergy Clin Immunol 2011; 11: 46-52.

35. Brannan JD, Gulliksson M, Anderson SD, et al. Evidence of mast cell activation and leukotriene release after mannitol inhalation. Eur Respir J 2003; 22: 491-496.

36. Brannan JD, Koskela H, Anderson SD. Monitoring asthma therapy using indirect bronchial provocation tests. Clin Respir J 2007; 1: 3-15.

37. Anderson SD, Charlton B, Weiler JM, et al. Comparison of mannitol and methacholine to predict exercise-induced bronchoconstriction and a clinical diagnosis of asthma. Respir Res 2009; 10: 4.

38. Kersten ET, Driessen JM, van der Berg JD, et al. Mannitol and exercise challenge tests in asthmatic children. Pediatr Pulmonol 2009; 44: 655-661.

39. Barben J, Roberts $M$, Chew N, et al. Repeatability of bronchial responsiveness to mannitol dry powder in children with asthma. Pediatr Pulmonol 2003; 36: 490-494.

40. Brannan JD, Anderson SD, Gomes K, et al. Fexofenadine decreases sensitivity to and montelukast improves recovery from inhaled mannitol. Am J Respir Crit Care Med 2001; 163: 1420-1425.

41. Wood LG, Powell H, Gibson PG. Mannitol challenge for assessment of airway responsiveness, airway inflammation and inflammatory phenotype in asthma. Clin Exp Allergy 2010; 40: 232-241.

42. de Nijs SB, Fens N, Lutter R, et al. Airway inflammation and mannitol challenge test in COPD. Respir Res 2011; 12: 11.

43. Brannan JD, Koskela H, Anderson SD, et al. Responsiveness to mannitol in asthmatic subjects with exercise- and hyperventilation-induced asthma. Am J Respir Crit Care Med 1998; 158: 1120-1126.

44. Munoz PA, Gomez FP, Manrique HA, et al. Pulmonary gas exchange response to exercise- and mannitol- induced bronchoconstriction in mild asthma. J Appl Physiol 2008; 105: 1477-1485.

45. Barben J, Kuehni C, Strippoli M-P, et al. Mannitol dry powder challenge in comparison with exercise-testing in children. Pediatr Pulmonol 2011; [Epub ahead of print; doi: 10.1002/ppul.21453].

46. Cowan SC, Hewitt RS, Cowan J0, et al. Exercise-induced wheeze: Fraction of exhaled nitric oxide directed managment Respirology. 2010; 15: 683-690. 